\title{
Targeting the Cancer Initiating Cell: The Ultimate Target for Cancer Therapy
}

\author{
James A. McCubrey ${ }^{1, *}$, Linda S. Steelman ${ }^{1}$, Stephen L. Abrams ${ }^{1}$, Negin Misaghian ${ }^{1}$, William H. Chappell ${ }^{1}$, \\ Jörg Bäsecke ${ }^{2}$, Ferdinando Nicoletti ${ }^{3}$, Massimo Libra ${ }^{3}$, Giovanni Ligresti ${ }^{3}$, Franca Stivala ${ }^{3}$, Danijela Maksi- \\ movic-Ivanic ${ }^{4}$, Sanja Mijatovic ${ }^{4}$, Giuseppe Montalto ${ }^{5}$, Melchiorre Cervello ${ }^{6}$, Piotr Laidler $^{7}$, Antonio Bonati ${ }^{8}$, \\ Camilla Evangelisti ${ }^{9}$, Lucio Cocco $^{10}$ and Alberto M. Martelli ${ }^{9,10}$
}

\begin{abstract}
${ }^{1}$ Department of Microbiology and Immunology, Brody School of Medicine at East Carolina University, Greenville, North Carolina USA 27858; ${ }^{2}$ Department of Medicine, University of Göttingen, Göttingen, Germany; ${ }^{3}$ Department of Biomedical Sciences, University of Catania, Catania, Italy; ${ }^{4}$ Department of Immunology, Instititue for Biological Research "Sinisa Stankovic", University of Belgrade, Belgrade, Serbia; ${ }^{5}$ Department of Clinical Medicine and Emerging Pathologies, University of Palermo, Palermo, Italy; ${ }^{6}$ Consiglio Nazionale delle Ricerche, Istituto di Biomedicina e Immunologia Molecolare "Alberto Monroy", Palermo, Italy; ${ }^{7}$ Department of Medical Biochemistry, Jagiellonian University Medical College, Krakow, Poland 31-034; ${ }^{8}$ University Hospital of Parma, Unit of Hematology and Bone-Marrow Transplantation, Parma 43100, Italy; ${ }^{9}$ IGM-CNR, IOR, Bologna, Italy; ${ }^{10}$ Dipartimento di Scienze Anatomiche Umane e Fisiopatologia dell'Apparato Locomotore, Università di Bologna, Bologna, Italy
\end{abstract}

\begin{abstract}
An area of therapeutic interest in cancer biology and treatment is targeting the cancer stem cell, more appropriately referred to as the cancer initiating cell (CIC). CICs comprise a subset of hierarchically organized, rare cancer cells with the ability to initiate cancer in xenografts in genetically modified murine models. CICs are thought to be responsible for tumor onset, self-renewal/maintenance, mutation accumulation and metastasis. CICs may lay dormant after various cancer therapies which eliminate the more rapidly proliferating bulk cancer (BC) mass. However, CICs may remerge after therapy is discontinued as they may represent cells which were either intrinsically resistant to the original therapeutic approach or they have acquired mutations which confer resistance to the primary therapy. In experimental mouse tumor transplant models, CICs have the ability to transfer the tumor to immunocompromised mice very efficiently while the BCs are not able to do so as effectively. Often CICs display increased expression of proteins involved in drug resistance and hence they are intrinsically resistant to many chemotherapeutic approaches. Furthermore, the CICs may be in a suspended state of proliferation and not sensitive to common chemotherapeutic and radiological approaches often employed to eliminate the rapidly proliferating BCs. Promising therapeutic approaches include the targeting of certain signal transduction pathways (e.g., RAC, WNT, PI3K, PML) with small molecule inhibitors or targeting specific cell-surface molecules (e.g., CD44), with effective cytotoxic antibodies. The existence of CICs could explain the high frequency of relapse and resistance to many currently used cancer therapies. New approaches should be developed to effectively target the CIC which could vastly improve cancer therapies and outcomes. This review will discuss recent concepts of targeting CICs in certain leukemia models.
\end{abstract}

Keywords: Therapeutic sensitivity, targeted therapy, PI3K, PTEN, Akt, mTOR.

\section{OVERVIEWS OF CANCER, STEM CELLS AND CANCER INITIATING CELLS (CICS)}

Cancer is a complex, multigenetic disorder characterized by uncontrolled proliferation, blockage in cellular differentiation, and metastases. Previously cancer biologists explained the process of cancer initiation and progression by means of a clonal/stochastic model. According to this model, a cell or a group of cells become tumorigenic after an initial somatic or germinal mutation, and subsequent series of genetic/epigenetic mutations, leading to proliferative and survival advantage of certain cell clones. This theory hypothesizes that the predominant clones with the capacity to produce identical neoplastic cells engender the tumor with the ability to produce initial neoplastic cells which maintain the tumor and capability to initiate other tumors after transplantation [1]. This clonal evolution model assumed that cancer was comprised of a clone or group of clones with similar growth rates that displayed a homogenous morphological pattern. Moreover this theory predicted that all cancer cells could randomly initiate and propagate the tumor by themselves [2-3]. However, this model has two fundamental limitations. First, not all neoplastic cells in a given tumor are homogenous and the differentiation patterns in tumors can be distinguished. Second, the clonal/stochastic model implies that every cancer cell could initiate a tumor. However, this tenant was not consistent with

*Address Correspondence to this author at the Department of Microbiology \& Immunology, Brody School of Medicine at East Carolina University, Greenville, NC, USA 27858; Tel: (252)-744-2704; Fax: (252)-744-3104;

E-mail: mccubreyj@ecu.edu the observation that a large number of cells were required to transfer a tumor.

Before we discuss cancer stem cells, we need to first very briefly describe normal stem cells. Stem cells are often defined by their potential for self-renewal and by their ability to proliferate and differentiate into diverse cell types. Since this review will cover in detail leukemia CICs, we will discuss hematopoietic stem cells (HSC). Normal HSCs have been characterized over the past 50 years [4]. HSCs comprise a very small, but essential, subpopulation of the total hematopoietic cell component, making up less than $0.01 \%$ of cells in the bone marrow of a normal individual [5]. Stem cells are also present in other tissue types (e.g., breast, prostate and other cell types), but often not as well characterized as HSCs.

A critical breakthrough in cancer research over the past 15 years has been the discovery of cancer initiating cells (CICs). These cells are also sometimes referred to as cancer stem cells; however, the adjective stem is now more frequently replaced with initiating as they lack certain key properties which true stem cells possess. Furthermore, the CICs may have suffered critical mutations which hopefully the "normal" stem cell lacks. The CIC concept entails that cancer initiation and propagation are driven by small subpopulations of cells displaying stem cell-like properties, such as the capability of self-renewal, asymmetric cell division and differentiation. CICs may arise from a normal stem cell and undergo epigenetic changes. CICs are likely capable of differentiating into a phenotypically diverse progeny which may ultimately form subsets of non-tumorigenic bulk cancer (BC) which have a limited capacity to 
divide and survive. CICs are resistant to conventional cytotoxic treatments. This resistance contributes tumor metastases and relapse. Conventional anti-tumor treatments, such as polychemotherapy, can only act on more mature BCs whereas CICs are normally resistant to these approaches, often due to the overexpression of proteins involved in drug resistance (see below) and their low proliferation rate.

CICs have been identified over the last decade in diverse cancer types and some of the key genes and signaling pathways responsible for their important cancer initiating and invasive properties are beginning to be elucidated [6-12].

Over the last 15 years, the CIC theory of cancer evolution has been proposed. This alternative model assumes the existence of a hierarchical order where a tissue-specific, programmed or reprogrammed cell, the so-called CIC, acquires or retains the properties of self-renewal, multi-lineage differentiation, and most importantly, tumor initiation, both in vitro and in vivo [13]. This population of rare cells is the only one capable of initiating and maintaining the tumor, thus allowing cancer diffusion to other organs, or cancer transplantation into other living beings, typically mice. According to the CIC model, the BCs would be transient amplifying cells and mature cells with limited or no ability whatsoever to initiate and/or maintain the tumor [14].

Such a model of cell organization, which is the basis for the definition of a CIC, is not new. It is thought to be the rule during embryonic development, and in various adult tissues, for example, in high-turnover tissues such as the lining epithelia and the bone marrow, with a hierarchical system based on the existence of a stem cell that displays self-renewal activity through asymmetric cell division and multi-potential differentiation ability. Thus, the CIC model of tumor biology entails the existence of a hierarchy of cells within a cancer that represents a caricature of cell hierarchies existing in normal tissues. CICs are at the apex of such hierarchy [15].

The fundamental clinical implications of a tumorigenic hierarchy within a tumor become apparent when considering that anticancer therapies are not selected for their discriminatory ability to target CICs. Therefore, if a given therapy fails to eliminate all the self-renewing CICs, residual surviving CICs will be able to repopulate the disease, causing tumor relapse [16].

Although mounting evidence supports the CIC model, it is important to be aware of a number of drawbacks that should be fully addressed. First, there is no evidence whatsoever that carcinogenic cells are significantly different from non-carcinogenic cells as a result of epigenetic rather than genetic changes [17-19]. Our current understanding of tumorigenesis is that cumulative mutations develop during cancer progression [20]. Therefore, at least in theory, these changes could result in more than one CIC population capable of maintaining and propagating the tumor, by developing a selfrenewal program. This theory is supported by the observation that there are neoplasias (for example pancreatic carcinoma or acute lymphoblastic leukemia, [ALL]) in which more than one phenotypically distinct population can initiate tumors in vivo [21]. Likewise, in acute myelogenous leukemia (AML), CICs (AML-CICs) undergo clonal evolution [22], while in chronic myelogenous leukemia (CML) one or more Imatinib-resistant CML-CIC subclones may be selected during therapy and progress to blast crisis (see below) [23-24].

Furthermore, there is evidence for chromosomal instability in the CICs derived from human metastatic colon carcinoma [25]. Based on these findings, a new CIC hypothesis should probably include both the stochastic/clonal evolution and the CIC hierarchical components [26].

Second, a lineage-committed progenitor cell can also function like a CIC by acquiring self-renewal, as demonstrated in both human CML [27] and a murine model of acute promyelocytic leukemia (APL) [28]. Third, the premise that transplanted CICs can re- capitulate the heterogeneity of the tumor from which they originated is usually based on limited analyses of a few surface markers [29]. It remains to be determined if there is also genetic heterogeneity within the primary tumor, that is not present after CIC xenotransplantation. Thus, it may be that the functional and phenotypic diversity within these neoplasias are underestimated. Fourth, a fundamental issue in the CIC model is related to the very low number of the CICs. The gold standard for estimating and quantifying CICs in vivo is limiting dilution followed by transplantation in Non Obese Diabetic/Severe Combined Immunodeficient (NOD/SCID) mice. This method could lead to underestimating the frequency of CICs in some cancer types, such as AML and melanomas, as seeding and tumor development in animals vary widely from case to case [30-33].

It has been proposed that xenotransplantation in animals which are not entirely immunodeficient may lead to underestimating the number of CICs in vivo. This may also depend on the fact that the microenvironment or the CIC niches (which clearly support CIC functions) are species-specific and often tumor-specific [34]. Hence, the mouse microenvironment/niche may differ in many aspects from the cancer microenvironment/niche sustaining CICs in the natural (human) host. Moreover, murine microenvironment/ niche receptors and cytokines may not necessarily cross-interact in all cases with the respective targets expressed in human CICs [35].

In light of these findings, there is certainly a need to re-evaluate the evidence which supports the CIC model using assays that could allow for a better engraftment of human cancer cells. In 1989, Hill and Milas suggested that mouse tumors contained stem cells and that the number of these cells within the tumor could be an important determinant of prognosis [36].

However, the first evidence of the existence of CICs/LSCs came from the seminal studies performed in human AML patients by Bonnet and Dick (see below) [37]. They demonstrated that leukemic CICs were capable of serially transferring AML into an immunodeficient mouse host. AML CICs were hierarchically organized and originated from a HSC rather than a committed progenitor cell. Leukemic CIC resided in the $\mathrm{CD} 34^{+} / \mathrm{CD} 38^{-} / \mathrm{Lin}^{-}$compartment (i.e. they are phenotypically similar to normal SCID repopulating cells), although exceptions to this rule have been reported [38]. The existence of leukemia CICs has been subsequently demonstrated in other malignant hematological disorders, including CML [39] and T-cell acute lymphoblastic leukemia (T-ALL) [40].

More than a decade after the identification of leukemic CICs, there is mounting evidence that CICs also exist in solid tumors. These include breast carcinoma [41], prostate carcinoma [42], pancreatic carcinoma [43], colon carcinoma [44], lung carcinoma [45], brain tumors (glioblastoma and medulloblastoma) [46], and hepatocellular carcinoma (HCC) [47]. However, compared with leukemias, the issue of solid tumor CICs still remains in its infancy.

The so-called side-population (SP) is thought to be enriched in CICs. SP cells actively extrudes the nuclear acid-staining dye Hoechst 33342 owing to high expression on their plasma membrane of drug resistance transporters of the $\mathrm{ABC}$ family such as $\mathrm{ABCB} 1$ and $\mathrm{ABCG} 2$, and can be easily identified by flow cytometry (See below) [48]. The enrichment of SP in leukemic CICs has been demonstrated in: multiple myeloma [49], T-ALL [50], AML [51], lung cancer [52], prostate cancer [53], breast cancer [54], glioblastoma [55], and HCC [56]. Intriguingly, it is emerging that in CICs, "stemness" genes are upregulated when compared with the main population. Accordingly, in the SP of liver cancer cell lines, the WNT pathway is highly expressed (See below) [57].

\section{INCREASED EXPRESSION OF PROTEINS INVOLVED IN DRUG RESISTANCE IN LEUKEMIA CICS}

Although CICs from various types of cancer have the potential for self-renewal, they spend the majority of their time in the $G_{0}$ 
phase of the cell cycle. This means that chemotherapeutic drugs, which act on cycling cell populations such as doxorubicin, are less effective on CICs than BCs [58]. Furthermore, the CICs are also often resistant to radiotherapy. The quiescent, non-cycling state of CICs may contribute to their resistance to conventional cancer treatments which target the rapidly proliferating cell. This quiescent nature of CICs may result in low rates of long-term remission and multi-drug resistance although, CICs also often display increased expression of drug transporter proteins.

Drug resistance can result from a plethora of mechanisms that include: decreased drug uptake, increased drug efflux, accelerated detoxification, defective apoptosis or altered expression of signaling pathways [59]. A single biochemical abnormality listed above may not be sufficient for drug resistance; there may be more than one component involved. Often these different biochemical properties can interact, either additively or synergistically and result in an increased drug resistant phenotype. ATP-dependent drug efflux is often observed clinically and is frequently linked to the increased expression of ATP-binding cassette $(\mathrm{ABC})$ transporter proteins [60]. This type of drug resistance occurs frequently in patients treated with drugs such as doxorubicin (a.k.a. Adriamycin). Patients with this type of drug resistance frequently develop "multi-drug" resistance as they become cross-resistant to drugs such as doxorubicin, daunorubicin, paclitaxel, etoposide and others which can be transported by the same drug transporter [MDR1 (multi-drug resistance-1 a.k.a., P-glycoprotein, Pgp), and multi-drug resistance association protein (MRP1) and others].

The ABC family of active drug transporters contains approximately forty-nine separate transmembrane proteins, many of which can function to efflux chemotherapeutic drugs [60-61]. Some of these proteins involved in transport are functional in diverse cell types and play critical roles in normal physiology by regulating the levels of a variety of nutrients and biologically active substances across cellular barriers. That is a key reason why it has been difficult to target "drug" transporters as they also regulate the levels of other types of molecules that are essential for normal physiology. The ABC family is divided into seven subfamilies: ABCA through ABCG. Several of these genes including $A B C G 1$ and $A B C B 1$ are expressed in immature $\mathrm{CD} 34^{+} \mathrm{CD} 38^{-}$hematopoietic cell fractions and are down-regulated upon differentiation into the more mature $\mathrm{CD} 34^{+} \mathrm{CD} 38^{+}$sub-population.

de Grouw and colleagues demonstrated that twenty-two ABC transporters were differentially expressed in AML CICs compared to AML BC. All the ABC transporters were expressed at lower levels in the more differentiated $\mathrm{CD} 34^{+} \mathrm{CD} 38^{+}$cells in comparison to the less differentiated $\mathrm{CD} 34^{+} \mathrm{CD} 38^{-}$cells [62]. $A B C B 1, A B C G 2$ and $A B C C 1$ are the three primary "multi-drug resistant" transporter genes that are expressed most frequently in tumor cells. Included in this sub-group are MDR1, BCRP (breast cancer resistance protein) and MRP1 [60]. These transporter proteins involved in drug efflux have been shown to confer drug resistance by mediating the active efflux of diverse anti-cancer drugs [63].

MDR expression is often higher in patients with secondary leukemias as compared with those in primary disease states [64]. Several potential drugs have been developed in attempts to block and compete with Pgp mediated drug efflux. Unfortunately, most of these MDR1 inhibitors have not proven effective [60,62,65-67]. Second generation MDR modulators have also yielded similar results [67]. MDR1 is not the only transporter which can efflux certain commonly-used chemotherapeutic drugs. Novel drugs that inhibit multiple transporters and other modes of drug-resistance might be more effective. Upon examination of the expression of various $\mathrm{ABC}$ transporters, a high redundancy was observed in both normal and early AML cells which may contain the AML CICs [62]. That is, the AML cells may overexpress more than one transporter which regulates the levels of a particular group of drugs. Current MDR modulators may be ineffective due to the expression of overlapping transporter proteins, which can efflux the same drug, thus making targeting of a single protein ineffective. Additionally, it is possible that irrelevant transporters were inhibited or there were pharmacokinetic interactions between the chemotherapeutic agent and the $\mathrm{ABC}$ transporter inhibitor. Third generation MDR modulators that are more powerful are being developed and examined in clinical settings [60] however, so far encouraging results have not been reported. Clearly the proteins involved in drug transport could be key targets for elimination of CICs, however, it is also evident that their targeting will be difficult as there are functional overlaps between the different transporters and these transporters also play other essential roles in physiology.

\section{EXPLOITING INCREASED EXPRESSION OF DRUG TRANSPORTERS AND ALDEHYDE DEHYDROGENASE TO IDENTIFY LEUKEMIA CICS}

The ability of CICs to efflux many drugs has been practically exploited in the isolation of CICs in different types of cancers. Many ABC transporters expressed in CICs efflux the fluorescent dyes Hoechst-33342 and rhodamine 123. This is in contrast to BCs, which retain the dyes. After Hoechst-33342 staining and flow cytometric analysis, a large percentage of CICs have been shown to reside in the SP cells. These SP cells were found in the bone marrow of over $80 \%$ of AML patients [60]. Identification of SP cells was one of the first techniques used to identify CICs from various different types of cancers.

CICs isolated from various cancer types also often express elevated aldehyde dehydrogenase activity (ALDH) and it is being used as a key marker for CIC identification [68]. AML patients who's CICs express elevated ALDH have a poorer prognosis than patients which express lower levels of ALDH [68]. Targeting of ALDH is complicated as it likely plays important functions in many different tissue types, not just CICs and there are at least twelve different ALDH isoforms.

\section{A WELL STUDIED MODEL FOR CICS AND THERAPY- CHRONIC MYELOID LEUKEMIA (CML)}

In the following section, we will discuss CML as it is a wellstudied leukemia which has had significant advances in therapy in the past 15 years due to the discovery of the effective BCR-ABL inhibitor, Imatinib as well as additional second and third generation inhibitors. Furthermore, CML, unlike AML and many other cancers, has a unique chromosomal translocation, $\mathrm{t}(9 ; 22)$, which is present in virtually $100 \%$ of CML patients [69]. As a result, part of the breakpoint cluster region $(B C R)$ gene from chromosome 22 is fused with the $c-A B L$ gene on chromosome 9. This abnormal "fusion" gene generates a protein of $210-\mathrm{kDa}$ (p210) or sometimes 190-kDa (p190).

CML is characterized by the overproduction of mature myeloid cells. This leukemia is subdivided into three distinct phases: chronic phase, accelerated phase and blast crisis, which is phenotypically similar to AML. While AML CICs are biologically and functionally distinct compared to HSC, CML CICs are often phenotypically similar to normal HSCs. CML CICs cells are present in $\mathrm{CD} 34^{+} \mathrm{CD} 38^{-}$cells and contain the $B C R A B L$ translocation present on what is historically referred to as the Philadelphia chromosome. CML patients have clonal expansion of hematopoietic cells that express the BCR-ABL proteins. Expression of BCR-ABL is essential for the sustained CML proliferation [70]. Current CML therapy is treatment with BCR-ABL kinase inhibitors. However acquired resistance to BCR-ABL kinase-inhibitor therapy can occur as well as a lack of sustained molecular remissions [63].

CML CICs are phenotypically CD $90^{+}$, Thy $1^{+}$and Lin. Blast crisis CML patients have higher levels of the progenitor pool $\left(\mathrm{CD} 34^{+} \mathrm{Lin}^{-}\right.$cells) than the other classes of CML patients. CML patients which are responsive to BCR-ABL targeted therapy, have fewer $\mathrm{CD} 34^{+} \mathrm{Lin}^{-}$cells in comparison to patients non-responsive to 
BCR-ABL inhibitors. The $\beta$-catenin pathway is overexpressed in patients resistant to BCR-ABL inhibitors $[27,71]$ and will be further discussed below. The differences in response in patients resistant to BCR-ABL kinase inhibitors as compared to those not resistant implies the acquisition of self-renewal capacity as well as other selective genetic changes in granulocyte-macrophage progenitors present in the CML CICs [27]. These results demonstrate the complex differences between CML CICs and BCs. While both cell types display enhanced proliferative capacity in comparison to normal myeloid cells, they display different growth properties in the presence of BCR-ABL inhibitors, which may be due to the presence of discrete additional mutations in the $B C R A B L$ gene present in the CML CICs (see below) or selection as a result of treatment.

Some of the CML CICs exhibit elevated BCR-ABL expression and changes in levels of the cytokines interleukin-3 and granulocyte colony stimulating factor (which may serve autocrine stimulatory roles), and the drug transporters $\mathrm{ABCB} 1 / \mathrm{MDR} 1, \mathrm{ABCG} 2$ and the transcription factor Oct-1 upon culture with reduced levels of growth factors [71]. Additional studies by Jiang et al., demonstrated that greater than seventy different $B C R A B L$ mutations were present in the progeny of cultured CML CICs [72]. This group has hypothesized that CML patients possess CICs, which have preexisting $B C R A B L$ kinase mutations before the advent of BCR-ABL inhibitor therapy; hence the patients already have some resistant CML CICs. As the CML CICs proliferate slowly, the patient may be initially responsive to therapy, then given time, CML CICs that are resistant to BCR-ABL inhibitors emerge (see discussion of mathematical models for CML presented below). This karyotype evolution of resistant cells from pre-existing CML CICs, which already have mutations in $B C R A B L$, is a lingering problem in BCRABL-directed therapy (15). Since CML CICs, like other CICs proliferate slowly, or are in a quiescent-like state, some investigators have proposed that a means to target these cells is to stimulate their proliferation and then treat with BCR-ABL inhibitors [73-74]. However, this therapeutic approach will only be appropriate if the CML CICs do not contain the T315I BCRABL mutation or a similar mutation, which confers resistance to many BCR-ABL inhibitors.

\section{MATHEMATICAL MODELING PROVIDES EVIDENCE FOR CML CICS}

Upon careful mathematical analysis of the CML incidence data and reappearance of the disease after discontinuation of therapy, it has been predicted that there are pre-existing CML CICs which are already resistant to BCR-ABL inhibitors such as Imatinib [75-78]. Basically upon analysis of the decrease in BCR-ABL mRNA transcripts upon and during the course of Imatinib treatment, a decrease to a low, constant level of BCR-ABL mRNA transcripts was observed as long as the drug Imatinib was effective, however once the patient was taken off Imatinib therapy, there was a dramatic, and rapid rebound in the level of $\mathrm{BCR}-\mathrm{ABL}$ mRNA transcripts which actually may exceed the initial levels of BCR-ABL mRNA transcripts. These results suggest the existence of CML CICs in the CML patients which were not eliminated by the Imatinib treatment. In addition, this model provides an explanation of the biphasic decrease of the BCR-ABL transcript upon initial therapy with Imatinib. Initially Imatinib quickly eliminates the terminally differentiated leukemic cells with an average lifespan of approximately twenty days which leads to a rapid decrease in the levels of BCRABL mRNA transcripts. However, after elimination of these differentiated cells, the less mature leukemic progenitors with an average lifespan of 125 days under Imatinib therapy are responsible for the slower but continued decrease of the BCR-ABL transcripts. The immature CML CICs are not sensitive to Imatinib, and expand gradually over time at a slow rate and are responsible for a rapid rebound of the leukemic burden upon cessation of Imatinib treatment which can exceed the initial level. Furthermore, if there are mutations present in the $B C R A B L$ gene which confers resistance to Imatinib, the emergence of this clone(s) appears and levels of BCR-
ABL mRNA transcripts increase even in the presence of Imatinib, again arguing for the presence of CML CICs in the CML leukemia patient. The models of Michor et al. also describe well the higher incidence of mutations in patients who receive therapy at a later stage of the disease. In these patients, the increased pool of CML CICs has a higher stochastic probability of mutations which then lead to a rapid expansion of resistant progenitors and treatment failure.

The quiescent nature of CML CICs may be responsible, in part, for the failure of Imatinib treatment to result in their total elimination. CML CICs may enter a dormant, Imatinib-resistant state or in some cases enter a proliferative Imatinib-sensitive state. Also CML CICs express higher levels of Pgp. Imatinib is a substrate for Pgp, thus with drug resistant CML CICs, Imatinib will not be an effective drug. Mathematical models, with various growth related parameters, have been proposed to explain the asymmetrical stem cell replication; however the biochemical mechanisms responsible for the asymmetry of CIC division are not well understood. Mutations occurring in the $B C R A B L$ gene are commonly thought to occur before disease onset and treatment, thus they are not believed to be responsible for the quiescence nature of the CML CICs. Cells containing mutant $B C R A B L$ genes may emerge later, due to the elimination of the cells with the wild type (WT) $B C R A B L$ gene upon Imatinib treatment. This model implies that the cells with the mutant $B C R A B L$ genes may not proliferate as well initially as the cells with the WT BCRABL gene. On the other hand, conflicting data indicate, that these mutations may confer a growth advantage, even without Imatinib treatment [79-80]. Clearly these models need further investigation. What are the key messages that we have learned from CML CICs? Many therapy-resistant CML CICs may already exist in the CML patient with key $B C R A B L$ mutations before therapy. After cessation of therapy these resistant CML-CICs may emerge and expand, perhaps in part due to the BCR-ABL treatment eliminating the CML BCs which were responsive to the therapy.

\section{INTERACTIONS OF BCR-ABL WITH DOWNSTREAM SIGNALING PATHWAYS LEADING TO IMATINIB RE- SISTANCE--POTENTIAL NOVEL TARGETS FOR THER- APY}

BCR-ABL induces multiple signaling pathways, that is probably why it is such a "potent" oncogene. Also it must be remembered that $\mathrm{BCR}-\mathrm{ABL}$ is not a normal protein in the cell, it is a chimeric protein encoded by the abnormal $B C R A B L$ chromosomal translocation. BCR-ABL can activate the RAS/RAF/MEK/ERK, PI3K/Akt, p38MAPK, JNK, FAK, SRC and RAC signaling cascades $[69,80]$. BCR-ABL can also interact with SRC-family kinase HCK which can lead to STAT5A activation that is JAK kinase-independent. This may be an important factor in the resistance of cells to Imatinib therapy (see below for section on SRC kinases) and also why it is appropriate to treat certain CMLs with SRC inhibitors such as Dasatinib. An important signaling family induced by BCR$\mathrm{ABL}$ is the RAC family of GTPases which was summarized in a recent review [80]. An overview of some of the signaling pathways activated in leukemic CIC is presented in Fig. (1). Also presented in this figure are the sites that small molecule inhibitors and antibodies may act.

$R A C$ is a multi-gene family which consists of $R A C 1, R A C 2$ and $R A C 3$. $R A C 1$ and $R A C 3$ are ubiquitously expressed while $R A C 2$ is expressed predominately in hematopoietic cells. BCR-ABL also interacts with RHO GTPases including RAC, RHO and CDC42. RAC-1, RAC-2 and to a lesser extent RAC-3 are detected at hyperactivated levels in HSCs and CML CICs. RAC-1 and RAC-2 cooperate with $\mathrm{BCR}-\mathrm{ABL}$ and induce a myeloproliferative disease of HSC origin. Deficiency of $R A C 1$ and $R A C 2$ in specific knock-out mice reduced the severity of BCR-ABL-mediated transformation and prolonged survival was observed [81-82]. RAC-3 may play an important role in the cancer development in the $B C R A B L, R a c$ - 


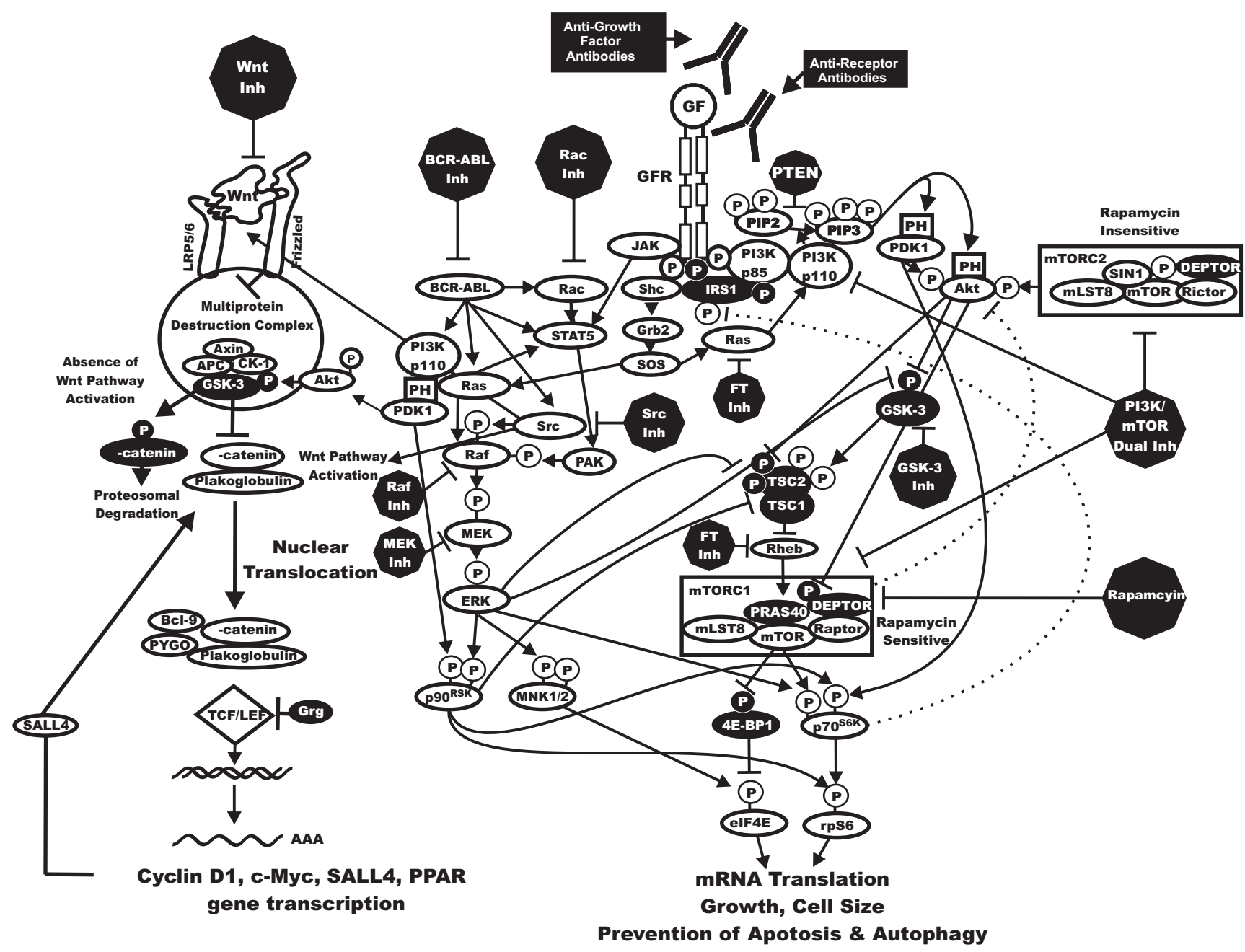

Fig. (1). Interactions between BCR-ABL, RAC, RAS/RAF/MEK/ERK, RAS/PI3K/PTEN/mTOR and Wnt/ק-Catenin Pathways that Result in the Regulation of Protein Translation and Gene Transcription in Leukemia CICs and Potential Sites of Interaction by Small Molecule Inhibitors. The Ras/Raf/MEK/ERK and Ras/PI3K/PTEN/Akt/mTOR pathways can affect protein translation by complex interactions regulating the mTORC1 and mTORC2 complexes. GF stimulation results in GFR activation which can activate the Ras/Raf/MEK/ERK and Ras/PI3K/PTEN/Akt/mTOR, JAK/STAT as well as other pathways. Chromosomal translocation such as BCR-ABL can activate these pathways as well as others including RAC and SRC. AKT can phosphorylate and inhibit the effects of GSK-3 $\beta$, TSC2 and PRAS-40, which result in mTORC1 activation. ERK and PDK1 can phosphorylate p90 ${ }^{\text {Rsk1 }}$, which in turn can phosphorylate and inhibit TSC2. AKT-mediated phosphorylation of GSK-3 $\beta$ also affects the WNT/ $\beta$-catenin pathway and epithelial mesenchymal transition (EMT). SRC also has effects on activation of the WNT/ $\beta$-catenin pathway. Rapamycin targets mTORC1 and inhibits its activity and also results in inhibition of downstream p70S6K. The effects of rapamycin are complex as long term administration of rapamycin may prevent mTOR from associating with mTORC2 and hence full activation of AKT is prevented. However, rapamycin treatment may result in activation of PI3K, by inhibiting the effects of p70S6K on IRS-1 phosphorylation which results in PI3K and AKT activation. Also rapamycin treatment may result in the activation of ERK in some cells, presumably by inhibition of the p70S6K mediated inhibition of IRS1. These later two effects of rapamycin could have positive effects on cell growth. Inhibition of PDK-1 activity can also result in activation of mTORC1, presumably by suppression of p70S6K and hence inhibition of IRS1 effects on PI3K activity. The PTEN, TSC1 and TSC2 tumor suppressor genes all converge on the mTORC1 complex to regulate protein translation. RHEB is a small G protein important for the regulation of mTORC1 \& 2 and is negatively regulated by TSC2 and is also subject to farnesylation. Thus the RAS/RAF/MEK/ERK and RAS/PI3K/PTEN/Akt/mTOR pathways can finely tune protein translation and cell growth by regulating mTORC1. Rapamycin can have diverse effects on these processes. Also these pathways can interact with the WNT/ $\beta$-catenin pathway which is important in developmental processes, EMT and CICs. Upon activation of the WNT pathway, $\beta$-catenin forms a complex with Bcl-9, PYGO, plakoglobulin and TCF/LEF which result in the transcription of critical genes including cyclin D1, c-Myc, SALL4 and PPAR $\delta$. The sites where key inhibitors targeting molecules are important in these pathways are indicated in black octagons with white lettering. FT = farnesyl transferase inhibitor.

1/Rac-2-deficient mice. These results suggest an important role for RAC GTPase in BCR-ABL-mediated CML CIC generation as well as in normal HSC functions. The RAC GTPases and RAS may be important in the induction of STAT5 which may be abnormally activated by various mechanisms, including an autocrine mechanism in Imatinib-resistant CML [83].

RAC proteins play key roles in the retention of murine HSC and may be an appropriate target to eliminate CICs $[82,84]$. The effects of an experimental RAC inhibitor (NSC23766) on HSC mobilization have been examined [82]. This inhibitor increased HSC mobilization, suppressed RAC activation and downstream p21 activated protein kinase (PAK) activation. NSC23766 also inhibited the growth of BCR-ABL- transformed cells, even those containing the Imatinib-resistant T315I mutation [85]. This RAC inhibitor may mobilize CML CICs from their niche and thus inhibit the stem cell 
properties of these cells. Hence, this inhibitor, unlike others such as Imatinib, may effectively target the CML CICs.

\section{ROLE OF SRC FAMILY KINASES IN CML AND ALL CICS}

Imatinib has proven highly effective in treatment of CML, however, Imatinib, by itself, will not cure CML. This is often due to the development of resistance in the CICs (as described above). SRC and other signaling pathways are involved in Imatinib resistance [86-87]. SRC family kinases are activated by BCR-ABL and inhibition of BCR-ABL by Imatinib may not result in the complete inhibition of SRC-family kinases. BCR-ABL is known to activate at least three SRC-family kinases (LYN, HCK and FGR) which are required for the development of BCR-ABL-mediated proliferation of preB-acute lymphoblastic leukemia (ALL), but not myeloid progenitor cells [88]. However, all three of these SRC-family kinases are activated by BCR-ABL in myeloid cells. BCR-ABL may directly interact with at least two SRC-family kinases (LYN and HCK) and alter their activities [89-90]. By performing genetic studies it was demonstrated that LYN, HCK and FYN are required by $\mathrm{BCR}-\mathrm{ABL}$ to induce CML to progress to lymphoid blast crisis in mice injected with BCR-ABL-transduced bone marrow [86].

As stated previously in this review, some CML CICs carrying $B C R A B L$ mutations such as $\mathrm{T} 315 \mathrm{I}$ are resistant to Imatinib, Dasatinib and other BCR-ABL inhibitors. However, in the studies by $\mathrm{Hu}$ et al., [86], they demonstrated that while BCR-ABL kinase inhibitors prolong the survival of CML mouse models, they do not completely eliminate CML CICs. In these studies, the structures of the $B C R A B L$ genes in CML CICs were determined and they did not have the BCRABL T315I mutation. These results strongly indicate that other mutations, can be involved in CML development and that Imatinib and Dastinib are not adequate to completely eliminate the CML CICs.

Alternatively, other genetic mutations occurring in blast crisis CML may contribute to the persistent activation of SRC. Mutations at other genes including, INK4a,RB and TP53 among others are involved in CML progression [91-93]. Loss of the $A R F$ gene enhances tumorigenicity of $B C R A B L$-transformed cells and limits the response to Imatinib in BCR-ABL-induced B-ALL mice [94]. Studies by $\mathrm{Hu}$ et al., [86] have demonstrated that the progression to lymphoid blast crisis requires activation of SRC family kinases and the SRC kinase inhibitor Dasatinib was more effective than Imatinib in preventing B-ALL, however, eventually the disease reoccurred. Furthermore, while Dasatinib treatment prolonged the life of the CML mice, it did not eradicate CML CICs cells. The authors have therefore suggested that an additional component of BCR-ABL-expressing CML CICs must be suppressed for complete eradication of the disease. Furthermore, certain $B C R A B L$ mutations such as T315I are resistant to Imatinib, Dasatinib and other BCR$\mathrm{ABL}$ inhibitors. Interesting, Aurora kinase inhibitors (VX-680) have shown promise in inhibiting Imatinib-resistant $B C R A B L$ T315I-transformed cells [95-96].

SRC kinases may induce the WNT/ $\beta$-catenin and RAF/MEK/ ERK signaling pathways which result in LEF/TCF activation [9798]. Activation of these and other signaling pathways may contribute to the survival of CICs (see below).

\section{INVOLVEMENT OF THE WNT/ $\beta$-CATENIN SIGNALING PATHWAY IN LEUKEMIA CICS}

The WNT signaling pathway plays a critical role in selfrenewal of HSCs and its dysregulation may be involved in CIC generation. There are approximately 20 WNT genes in the human genome and they encode lipid-modified secreted glycoproteins [99]. WNT induces cell signaling to a receptor complex consisting of a Frizzled family receptor and a co-receptor of the LDL-receptor related protein family, usually LRP5 or LRP6. This can result in the destabilization of the multiprotein destruction complex (MDC) and the subsequent stabilization of $\beta$-catenin. $\beta$-catenin normally has a very short half life. In the absence of WNT, $\beta$-catenin is normally phosphorylated by components of the MDC including: axin, adenomatous polyposis coli (APC), glycogen synthase kinase $3 \beta$ $(\mathrm{GSK}-3 \beta)$ and casein kinase 1 (CK1). When $\beta$-catenin is phosphorylated by these kinases, it is targeted for proteasomal degradation Fig. (1).

In contrast, if cytoplasmic $\beta$-catenin is stabilized by WNT signaling (that is not phosphorylated by the MDC complex); it migrates to the nucleus and replaces the groucho-related repressors present on certain genes. $\beta$-catenin in the presence of the accessory proteins BCL-9, PYGO (pygopus) and the TCF/LEF (T-cell factor/lymphocyte-enhancer-binding factor) forms a complex which results in transcription of important growth promoting genes such as $C M Y C$ and CYCLIN-D1 (CCND1). Furthermore, TCF/LEF can result in an increase in SALL4 expression which is an oncogene that can bind to $\beta$-catenin and enhance its activity. Plakoglobin is another important component of WNT signaling. It is a co-inducer of TCF/LEF transcriptional activation and stimulates the transcription of CYCLIN-D1, c-MYC and perxosome proliferator-activated receptor-delta (PPAR $\delta$ ). Plakoglobulin expression is enhanced by certain AML fusion proteins. The WNT pathway is frequently dysregulated in AML [27].

The WNT pathway is regulated by many different inhibitors which have been shown to have important roles in oncogenesis. These interactions are well described in the above mentioned comprehensive review by Mikesch et al., [99]. Some key inhibitors include members of the Dickkopf (DKK) family which interact with LRP5/6 and prevent the transmission of signals from the Frizzled-LRP complex. The WNT inhibitor factor 1 (WIF-1) is another inhibitor of the WNT pathway. It is an extracellular protein which binds to WNT, thereby inhibiting the WNT pathways [100]. The promoter region of WIF1 is hypermethylated in many APLs and associated with a poorer disease free three year survival rate than in patients without WIF-1 promoter methylation [101].

Importantly, this pathway has been shown to have critical roles in self renewal of HSC and CICs [102-104]. WNT expression inhibits the differentiation of HCS [104-105]. Overexpression of axin, a component of the MDC, inhibits WNT signaling and in turn this results in decreased growth of HSC [102]. Constitutive overexpression of activated $\beta$-catenin increased the frequency of HSC and prevented their differentiation [102].

Specific deletion of $\beta$-catenin (CTNNB1) in hematopoietic lineages in mice did not prevent the formation of HSC, however, the HSC were deficient in long-term growth and maintenance [103]. The target(s) for CML CICs and BCR-ABL-transformation were greatly reduced while the induction of ALL occurred fairly normally. These and other results suggest that ALL may arise from a more mature stem cell committed to the B cell lineage. Conditional deletion of $\beta$-catenin (CTNNB1) decreased the self-renewal ability of CML CICs. Thus $\beta$-catenin was necessary for the increased selfrenewal capacity conferred by the introduced $B C R A B L$ oncogene on the target stem cells to permit transformation to proceed along the myeloid lineage. The authors demonstrated that BCR-ABL phosphorylation was decreased in the $\beta$-catenin-deficient mice which also resulted in lower levels of phosphorylated STAT5a. $\mathrm{BCR}-\mathrm{ABL}$ and $\beta$-catenin form a complex and the authors have suggested that this complex may stabilize BCR-ABL [106]. Reduction of the BCR-ABL: $\beta$-catenin complex could result in a decrease in the phosphorylation of BCR-ABL targets such as STAT5a and decrease CML self renewal and disease progression. These important results provide further evidence of the role of $\beta$-catenin and the WNT pathway in normal HSC as well as CML CICs and demonstrate the stem cell origin of CML but not ALL. WNT signaling may be critical for BCR-ABL stability and the maintenance of CML CICs. The WNT pathway may serve to differentiate CML and ALL. The successful development of WNT inhibitors may serve to augment the ability of $\mathrm{BCR}-\mathrm{ABL}$ inhibitors to eradicate CML. 
WNT inhibitors are being developed by several pharmaceutical and biotechnological companies; however, there do not appear to be any peer-reviewed papers documenting their effectiveness.

Not unexpectedly, the WNT signaling pathway interacts with other signaling pathways including Notch, sonic hedgehog and PI3K/AKT [106-108]. Increased FLT-3 signaling in AML patients with mutations/amplifications of FLT3 may result from AKT mediated phosphorylation and inactivation of GSK-3 $\beta$ which results in higher levels of WNT signaling and stabilized $\beta$-catenin [109]. Alternatively, Frizzled-4, a WNT receptor, is induced by certain FLT3 mutations which lead to increased $\beta$-catenin levels that result in augmented TCF/LEF activity and $\mathrm{c}-M Y C$ transcription [110$111]$.

\section{INTERACTIONS BETWEEN CICS AND THEIR MICRO- ENVIRONMENT AND POTENTIAL MOLECULES FOR TARGETING}

Whether CICs also depend on their particular niche for selfrenewal is currently unclear. While there are clear differences between normal stem cells and CICs, there are also striking similarities. Some molecular mechanisms that enable self-renewal in normal stem cells may exist in CICs.

Indeed, both normal HSC and leukemic CICs depend on stromal cell derived factor-1 (SDF-1)-mediated CXCR4 (CXC chemokine receptor-4 which is specific for SDF-1) signaling for homing and mobilization [112]. WNT-induced $\beta$-catenin signaling has been implicated in the maintenance and expansion of murine HSCs, whereas inhibition of the $\beta$-catenin pathway severely impaired the self-renewal capacity of CML CICs $[27,102,113]$. The adhesion of normal $\mathrm{CD} 34^{+}$stem/progenitor cells to bone marrow stroma and fibronectin is mediated by the integrins VLA-4 and VLA-5, and a similar role is fulfilled by integrins in leukemic cells [114-115]. Thus, many of the molecules that mediate the interaction between stem cells and the bone marrow niche are utilized by both normal HSC cells and CML CICs.

Whether the leukemic CIC needs collaborative genetic hits to improve their interactions with the extrinsic stem cell niche remains an intriguing question. One possibility is that CICs migrate more when compared with normal HSCs that allowing the CICs to escape growth inhibition or quiescence promoting signals induced by osteoblasts and stromal cells in the niche. Many membrane-associated ligands are normally present in the niche, and they can be cleaved by matrix metallo-proteinases (MMPs). MMPs and their tissue inhibitors (TIMPs) are important in the progression and invasiveness of many malignant disorders. The expression of MMPs such as MMP9 is often elevated in AML blasts [116]. MMPs may increase the soluble concentrations of activated ligands to enable leukemic CIC self-renewal or expansion outside the niche. Therefore, the level of marrow MMP-9 may be a useful surrogate marker for monitoring disease status in AML and it was proposed as a potential prognostic factor. Targeted inhibition of MMPs may inhibit CIC expansion and may prove useful in leukemia therapy.

Targeting CD44 with a monoclonal antibody could suppress both AML and CML progression and induce differentiation [117119]. The monoclonal anti-CD44 Ab may disrupt interactions between the CICs and the bone marrow niche. RAC inhibitors may also disrupt these interactions and mobilize LSC (see below).

\section{SUPPRESSING CICS: TARGETING THE PI3K/PTEN/ AKT/MTOR PATHWAY}

The PI3K/PTEN/Akt/mTOR pathway, and specifically PTEN levels, may be critical for the development of CICs [120-137].

The concept that the PI3K/PTEN/Akt/mTOR pathway serves as a therapeutic target in leukemia CICs is beginning to emerge. CICs have unique properties as they can be both quiescent and also resistant to chemotherapeutic and hormonal based drugs. However, under certain conditions, they resume proliferation and hence could be potentially susceptible to PI3K, AKT or mTOR inhibitors.

The PTEN gene exerts effects on CICs, especially in hematopoietic and breast cells. In conditional PTEN knock-out mice, upon inactivation of PTEN, there was a transient increase in hematopoietic CICs and a myeloproliferative disease develops and the mice subsequently developed leukemia after 4-6 weeks [120]. If the mice were treated with the mTOR inhibitor rapamycin, the myeloproliferative disorder and leukemia were prevented. The initial leukemic CICs that arose after conditional PTEN deletion by themselves were not able to induce leukemia upon transfer into SCIDrecipient mice, but if the leukemic CICs were derived from the $P T E N$-conditional mice that had developed leukemia, they were able to transfer leukemia to the SCID-recipient mice, which could be prevented by rapamycin treatment. Also the normal HSC from the PTEN-conditional knock-out mice repopulated the hematopoietic cell component of irradiated mice treated with rapamycin indicating that it was possible to selectively eliminate leukemic CICs. However, rapamycin treatment did not eradicate the PTENdeficient leukemia CICs after leukemia onset.

PTEN plays critical roles in regulating cell cycle progression in HSC and other cells. PTEN influences the decision of whether the cells remain in quiescence $\left(G_{0}\right)$ or enter $G_{1}$ and also controls the subsequent speed of proliferation [128]. Importantly PTEN influences hematopoietic differentiation and PTEN-deficiency blocks differentiation of $\mathrm{B}$ lymphoid stage resulting in an increase in the presence of myeloid and $\mathrm{T}$ cells but a decrease in cells of the $\mathrm{B}$ lineage.

Additional studies have identified some of the genes which can interact with PTEN deletion to influence leukemogenesis [130]. The authors demonstrated that PTEN-deletion induced the expression of p16 $6^{\text {Ink4a }}$ and TP53 in the HSC and p19 $9^{\text {Arf }}$ and TP53 in other hematopoietic cells. Functional TP53 suppressed leukemogenesis in PTEN-deficient mice and also promoted HSC depeletion. While p16 $6^{\text {Ink4a }}$ also stimulated HSC depletion, it had a limited role in suppressing leukemia development. In contrast, p19 ${ }^{\text {Arf }}$ strongly suppressed leukemia development but did not decrease HSC levels. The authors demonstrated that in the PTEN-mutant mice, secondary mutations inhibited the tumor suppressor response. Therefore in the leukemic clones that arose in these PTEN-deficient mice, mTOR activation depleted HSC by a tumor suppressor response which was inhibited by secondary mutations. These authors did not observe a role for reactive oxygen species (ROS) in the depletion of HSCs in $P T E N$-deficient mice. In contrast, other studies have suggested roles for ROS in depletion of TSC1-deficient HSCs [131]. In these studies, TSC1 depletion led to mTOR activation, exit from quiescence, increased proliferation but resulted in exhaustion of HSCs without the development of leukemia.

Other genes in this pathway also have been shown to have effects on HSC depletion. TSC1-deficient mice result in increased $\mathrm{PI} 3 \mathrm{~K} / \mathrm{PTEN} / \mathrm{Akt} / \mathrm{mTOR}$ signaling which leads initially to increased HSC cell cycling and mobilization then to progressive depletion and defective long term repopulation [132]. These authors also demonstrated that TSC1 regulation of HSC mobilization is also effected by mTORC1-independent mechanisms and that one of the genes involved is the actin-bundling protein FSCN1 (fascin). Fascin is believed to be an important mTORC1-independent mediator of the effects of TSC1 on the regulation of HSC mobilization. FSCN1 plays important roles in controlling cytoskeleton organization and motility and is upregulated in many human cancers. Fascin promotes cell migration and invasion [133]. TSC1 regulation of fascin may play important roles in the dissemination of leukemia CICs. This is an interesting observation as in solid tumor CICs; a frequent observation is the formation of sphere-like cells (e.g., mammospheres) and masses. FOXO is also an important regulator of HSC homeostasis. FOXO is essential for long-term HSC regeneration. 
FOXO regulates quiescence and survival in response to oxidative stress [134-135].

\section{SUPPRESSING CICS: TARGETING PML}

Targeting of PML also leads to increased HSC cycling and to mTOR-mediated HSC depletion [136]. The PML gene is involved in the $\mathrm{t}(15: 17)$ chromosomal translocation found in acute promyelocytic leukemia (APL). PML encodes a protein which localizes to PML nuclear bodies. PML is a tumor suppressor and controls many processes including apoptosis, proliferation and senescence. PML is reported to have diverse biological functions and is a negative regulator of the AKT/mTOR pathway at multiple levels including opposing the nuclear function of AKT, repressing mTOR activity by inhibition of RHEB/mTOR in hypoxia and regulating PTEN localization through modulation of a deubiquitination network [128]. PML is highly expressed in HSCs and there are more PML nuclear bodies in the HSC than in the committed cell populations. PML expression decreases as the HSC differentiate. PML also has consequences on the outcome of CML. CML blasts express high amounts of PML which is regulated at the transcriptional level. PML loss or lower expression predicts a better prognosis in CML [128,137]. Recently it has been shown that PML is a negative regulator of mTOR [137]. PML is important in HSC maintenance and $P M L^{-/}$ HSC display increased cycling compared to HSC from normal mice, but the $P M L^{-/}$HSC lack long-term repopulating capacity which is likely due to defective maintenance of quiescence. Conditional ablation of PTEN in the hematopoietic system of mice drives exit from quiescence, exhaustion of normal HSC, and generation of leukemia CICs via activation of the PI3K/Akt/mTOR pathway. Likewise loss of PML enhances the cycling pool of HSCs though mTOR activity. However, an important difference between $P M L^{-/}$ and conditional ablation of PTEN is that $P M L^{-/}$mice do not develop leukemia, whereas in mice where PTEN is conditionallyablated, leukemia develops [128]. The exit from quiescence is more profound in leukemia CICs from $P M L^{-/}$mice than in HSC from $P M L^{-/}$mice, indicating a potential difference which could be exploited for therapy. Rapamycin opposes leukemogenesis in PTENconditional knock-out mice and restores normal HSC function. In contrast, rapamycin restores leukemia CIC maintenance in the $P M L^{-/}$model.

PML expression is high in leukemia CICs [136]. PML is very important for leukemia CIC maintenance. Leukemia CICs from $P M L^{-/-}$mice were generated by infection with a retrovirus encoding BCR-ABL. Similar to HSC isolated from $P M L^{-/}$mice, leukemic CICs from $P M L^{-/}$mice undergo intensive cell cycling, but displayed reduction of long-term transfer of CML disease (in the third serial bone marrow transplant), failed to generate minimal residual disease and impairment of leukemia CIC maintenance.

Arsenic trioxide $\left(\mathrm{As}_{2} \mathrm{O}_{3}\right)$ selectively targets PML for degradation. $\mathrm{As}_{2} \mathrm{O}_{3}$ specifically targets $\mathrm{KSL}\left(\mathrm{c}-\underline{\mathrm{Kit}}{ }^{+}, \underline{\mathrm{S}} \mathrm{ca}-1^{+}, \underline{\mathrm{Lin}}{ }^{-}\right)$cells and reduced their colony forming ability but did not affect KSL cells isolated from $P M L^{-/-}$mice.

Increased mTOR activity was observed in HSC prepared from $P M L^{-/}$vs. WT mice. Rapamycin treatment restored the colony forming ability of $P M L^{-/}$HSC and rescued the phenotype of $P M L^{-/}$ HSCs and leukemia CICs [136]. Rapamycin increased the quiescence of PML ${ }^{-/-}$HSCs. PML has an important role in maintenance of HSCs by repressing mTOR activity. Rapamycin also had effects of $P M L^{-/-}$leukemia CICs. It restored their ability in long term colony formation assays. PML downregulation eliminates leukemia CICs.

$\mathrm{As}_{2} \mathrm{O}_{3}$ reduced PML levels in leukemic CICs and decreased the number of quiescent CIC in the absence of the induction of apoptosis [128,136-137]. Consistent with these results, the long-term maintenance of the CIC was dramatically suppressed. The authors examined the effects of cytosine arabinoside (Ara-C) and $\mathrm{As}_{2} \mathrm{O}_{3}$ on leukemia CICs. They hypothesized that interventions that increase the cycling of quiescence CIC might enhance their death by chemotherapeutic agents. The combined treatment resulted in eradication of the CICs even after 4 weeks after termination of treatment and long term repopulating assays could not detect the presence of CICs or the presence of minimal residual disease.

Importantly the authors demonstrated that the HSC and leukemic CICs display some important differences. Namely there were fewer quiescent cells in BCR-ABL- expressing CICs than in control KSL HSC, suggesting that the reservoir of quiescent cells is higher in normal HSC than in CICs [128,136-137]. Furthermore the $\mathrm{As}_{2} \mathrm{O}_{3}$-induced exit from quiescence was more profound in the CICs than in the HSC. The authors also confirmed some of these important observations on CICs and HSCs isolated from human CML patients and normal volunteers respectively. These studies indicate the potential therapeutic approaches of combining PMLreducing drugs and chemotherapeutic drugs for certain leukemia therapies.

The PI3K/PTEN/Akt/mTOR pathway may mediate HSC activity through AKT/FOXO instead of mTOR [134-135]. PML may oppose mTOR as well as AKT/FOXO and hence is a critical regulator of HSC and leukemia CICs.

\section{EFFECTS OF AGE OF CICS ON MALIGNANT POTEN- TIAL}

Recently is has been shown in certain animal models that there is a correlation between the age of the induction of leukemia and the rapidity of development of the leukemia [138]. In these studies it was determined that the age of the recipient mice did not alter the potential for leukemia after injection of $B C R A B L$-transformed $\mathrm{BaF} / 3$ cells, namely, both young and old mice developed leukemia at approximately the same time. However, in a conditional $B C R A B L$-mouse model (CombitTA-BCR-ABLp190) where the expression BCR-ABL could be regulated by controlling the presence or absence of doxycline (tetracycline-repressor system), it was observed that leukemia (B-ALL) was more rapid when BCR-ABL was induced by removing doxycline from the drinking water at either 12 or 20 months of age than when BCR-ABL was induced in 4 months of age. This may result from the selection of CICs with a more potential malignant phenotype in the older mice. Alternatively there may be more complimenting mutations in the CICs present in older mice which can interact with BCR-ABL to result in more aggressive CICs than in the CICs present in younger mice.

\section{CANCER INITIATING CELLS IN SOLID CANCERS}

CICs have been identified in many different solid tumors including, breast, prostate, colon, hepatocellular carcinoma, pancreatic, glioblastoma, melanoma and others [122-129, 139-143]. Some of these CICs (e.g., colorectal CICs) express one or multiple cell surface markers associated with stemness such as CD122, CD44, CD24, CD29, CD166 and Lgr5 [139]. The targeting of certain of these molecules may eliminate CICs [139]. The PI3K/PTEN/ Akt/mTOR Pathway has been shown to be important in multiple cancer types including breast cancer [121-122, 143-144]. Targeting this pathway may be an appropriate approach to eliminate CICs.

\section{CONCLUSIONS}

CICs are thought to be the essential fraction of the tumor that is responsible for the integrity of the tumor. That is, the CICs can reestablish the tumor after removal of the original tumor by chemoor radio-therapy or surgical approaches. Experimentally, the CICs can transfer the tumor more effectively to recipients than the bulk of the more differentiated tumor mass. CICs differ from BC as the CICs have retained certain essential properties of stem cells and the CICs are normally dormant or slowly replicating while the BCs are more rapidly proliferating. Importantly the CICs can undergo differentiation and give rise to the differentiated cells present in the original cancer as well as therapy-resistant cells. Therapy-resistant 
cells may result from mutations that occur in the CICs during the original cancer treatment, or they may be a sub-population of CICs which already contain the mutation and hence are selected for during the therapy. The key dilemma with CICs is that they are often refractory to most common anti-cancer approaches such as chemo-, radio-, or hormone based therapies. However, CICs may show some sensitivity to certain novel therapies. Development of novel approaches to target CICs could significantly enhance cancer therapy. In summary, the specific therapeutic targeting of leukemia CICs is a field in its infancy. The tumor cell microenvironment or niche may also be an important therapeutic target and Rac inhibitors as well as various anti-integrin antibodies may be appropriate. Recently the WNT- $\beta$-catenin and PI3K/PTEN/Akt/mTOR and PML pathways have been shown to be important in leukemia CICs. Targeting these pathways may enhance leukemia therapy. As we learn more about the various leukemic CICs, it undoubtedly will result in novel ways to treat leukemias. Certain natural products commonly used in traditional medicine may prove effective in interacting with chemotherapeutic drugs to target leukemia CICs. Drugs such as $\mathrm{As}_{2} \mathrm{O}_{3}$ may target critical proteins involved in CIC proliferation. Leukemia CICs pose challenges to classical chemotherapeutic approaches due their slow rate of proliferation and quiescent-like properties. Additionally, the increased expression of $\mathrm{ABC}$ transporter proteins and various cell-signaling pathways further adds complexity to the situation. However, their pivotal role in the overall control and propagation of a variety of cancers and some initial responses to various inhibitors and treatments shows their therapeutic potential. Ultimately, previous research has shown that we must be clever and multi-faceted in our approach to design therapies, which may be effective in selectively eliminating these leukemia CICs.

\section{ACKNOWLEDGEMENTS}

This work was supported in part by grants from: Fondazione Carisbo (to LC), MinSan 2008 "Molecular therapy in paediatric sarcomas and leukemias against IGF-1 receptor system" (to AMM), PRIN 2008 (to AMM) and FIRB 2010 (RBAP10447J, to AMM and LC).

\section{DISCLOSURE}

This manuscript is an updated version of our previous review article [126] published in 2009 and contains significant new information as well as new scientific references.

\section{REFERENCES}

[1] Campbell LL, Polyak K. Breast tumor heterogeneity: cancer stem cells or clonal evolution? Cell Cycle 2007; 6: 2332-8.

[2] Dick JE. Stem cells: Self-renewal written in blood. Nature 2003; 423: 231-3.

[3] Dick JE. Breast cancer stem cells revealed. Proc Natl Acad Sci USA 2003; 100: 3547-9.

[4] Till JE, McCulloch EA. A direct measurement of the radiation sensitivity of normal mouse bone marrow cells. Radiat Res 1961; 14: 213-22.

[5] Rizo A, Vellenga E, de Haan G, Schuringa JJ. Signaling pathways in self-renewing hematopoietic and leukemic stem cells: do all stem cells need a niche? Hum Mol Genet 2006; 15: R210-9.

[6] Lapidot T, Sirard C, Vormoor J, et al. A cell initiating human acute myeloid leukaemia after transplantation into SCID mice. Nature 1994; 367: 645-48.

[7] Bonnet D, Dick JE. Human acute myeloid leukemia is organized as a hierarchy that originates from a primitive hematopoietic cell. Nat Med 1997; 3: 730-7.

[8] Al-Hajj M, Wicha MS, Benito-Hernandez A, Morrison SJ, Clarke MF. Prospective identification of tumorigenic breast cancer cells. Proc Natl Acad Sci USA 2003; 100: 3983-8.

[9] Polyak K, Weinberg RA. Transitions between epithelial and mesenchymal states: acquisition of malignant and stem cells. Nature Reviews Cancer 2009; 9: 265-3
[10] Mailtand NJ, Collins AT. Prostate cancer stem cells: A new target of therapy. J Clin Oncol 2007; 26: 2862-70.

[11] Lawson DA, Witte ON. Stem cells in prostate cancer initiation and progression. J Clin Invest 2007; 117: 2044-50.

[12] Marian CO, Shay JW. Prostate tumor-initiating cells: A new target for telomerase inhibition therapy? Biochimica et Biophysica Acta 2009; 1792: 289-96.

[13] Reya T, Morrison SJ, Clarke MF, Weissman IL. Stem cells, cancer and cancer stem cells. Nature 2001; 414: 105-11.

[14] Sullivan JP, Minna JD, Shay JW. Evidence for self-renewing lung cancer stem cells and their implications in tumor initiation, progression, and targeted therapy. Cancer Metastasis Rev 2010; 29: 61-72.

[15] Chiu PP, Jiang H, Dick JE. Leukemia-initiating cells in human T lymphoblastic leukemia exhibit glucocorticoid resistance. Blood 2010; 116: 5268-79.

[16] Sehl ME, Sinsheimer JS, Zhou H, Lange KL. Differential destruction of stem cells: implications for targeted cancer stem cell therapy. Cancer Res 2009; 69: 9481-9.

[17] Dick JE. Stem cell concepts renew cancer research. Blood 2008; 112: 4793-807.

[18] Visvader JE, Lindeman GJ. Cancer stem cells in solid tumours: accumulating evidence and unresolved questions. Nat Rev Cancer 2008; 8: 755-68.

[19] Rosen JM, Jordan CT. The increasing complexity of the cancer stem cell paradigm. Science 2009; 324: 1670-3.

[20] Gilliland DG, Griffin JD. The roles of FLT3 in hematopoiesis and leukemia. Blood 2002; 100: 1532-42.

[21] Hermann PC, Huber SL, Herrler T, et al. Distinct populations of cancer stem cells determine tumor growth and metastatic activity in human pancreatic cancer. Cell Stem Cell 2007; 1: 313-23

[22] Barabe F, Kennedy, JA, Hope KJ, Dick J.E. Modeling the initiation and progression of human acute leukemia in mice. Science 2007; 316: 600-4.

[23] Shah NP, Nicoll JM, Nagar B, et al. Multiple BCR-ABL kinase domain mutations confer polyclonal resistance to the tyrosine kinase inhibitor imatinib (STI571) in chronic phase and blast crisis chronic myeloid leukemia. Cancer Cell 2002; 2: 117-25.

[24] Lemoli RM, Salvestrini V, Bianchi E, et al. Molecular and functional analysis of the stem cell compartment of chronic myelogenous leukemia reveals the presence of a CD34- cell population with intrinsic resistance to imatinib. Blood 2009; 114: 5191-200.

[25] Odoux C, Fohrer H, Hoppo T, et al. A stochastic model for cancer stem cell origin in metastatic colon cancer. Cancer Res 2008; 68 : 6932-41.

[26] Takebe N, Ivy SP. Controversies in cancer stem cells: targeting embryonic signaling pathways. Clin Cancer Res 2010; 16: 3106-12.

[27] Jamieson CH, Ailles LE, Dylla SJ, et al. Granulocyte-macrophage progenitors as candidate leukemic stem cells in blast-crisis CML. N Engl J Med 2004; 351: 657-67.

[28] Guibal FC, Alberich-Jorda M, Hirai H, et al. Identification of a myeloid committed progenitor as the cancer-initiating cell in acute promyelocytic leukemia. Blood, 2009, 114, 5415-25.

[29] Zhou BB, Zhang H, Damelin M, Geles KG, Grindley JC, Dirks PB Tumour-initiating cells: challenges and opportunities for anticancer drug discovery. Nat Rev Cancer 2009; 8: 806-23.

[30] Kelly PN, Dakic A, Adams JM, Nutt SL, Strasser A. Tumor growth need not be driven by rare cancer stem cells. Science 2007; 317 337.

[31] Hope KJ, Jin L, Dick JE. Acute myeloid leukemia originates from a hierarchy of leukemic stem cell classes that differ in self-renewal capacity. Nat Immunol 2004; 5: 738-43.

[32] Jin L, Lee EM, Ramshaw HS, et al. Monoclonal antibody-mediated targeting of CD123, IL-3 receptor alpha chain, eliminates human acute myeloid leukemic stem cells. Cell Stem Cell 2009: 5: 31-42.

[33] Quintana E, Shackleton M, Sabel MS, Fullen DR, Johnson TM, Morrison SJ. Efficient tumour formation by single human melanoma cells. Nature 2008; 456: 593-8.

[34] Labarge MA. The difficulty of targeting cancer stem cell niches. Clin Cancer Res 2010; 16: 3121-9.

[35] Bonnet D, Bhatia M, Wang JC, Kapp U, Dick JE. Cytokine treatment or accessory cells are required to initiate engraftment of purified primitive human hematopoietic cells transplanted at limiting doses into NOD/SCID mice. Bone Marrow Transplant 1999; 23: 203-9. 
[36] Hill RP, Milas L. The proportion of stem cells in murine tumors. Int J Radiat Oncol Biol Phys 1989; 16: 513-18.

[37] Bonnet D, Dick JE. Human acute myeloid leukemia is organized as a hierarchy that originates from a primitive hematopoietic cell. Nat Med 1997; 3: 730-7.

[38] Taussig DC, Miraki-Moud F, Anjos-Afonso F, et al. Anti-CD38 antibody-mediated clearance of human repopulating cells masks the heterogeneity of leukemia-initiatingcells. Blood 2008; 112: 568-75.

[39] Abrahamsson AE, Geron I, Gotlib J, et al. Glycogen synthase kinase 3 beta missplicing contributes to leukemia stem cell generation. Proc Natl Acad Sci USA 2009; 106: 3925-9.

[40] Cox CV, Martin HM, Kearns PR, Virgo P, Evely RS, Blair A. Characterization of a progenitor cell population in childhood T-cell acute lymphoblastic leukemia. Blood 2007; 109: 674-82.

[41] Park SY, Lee HE, Li H, Shipitsin M, Gelman R, Polyak K. Heterogeneity for stem cell-related markers according to tumor subtype and histologic stage in breast cancer. Clin Cancer Res 2010; 16: 876-87.

[42] Eaton CL, Colombel M, van der Pluijm G, et al. Evaluation of the frequency of putative prostate cancer stem cells in primary and metastatic prostate cancer. Prostate 2010; 70: 875-82.

[43] Li C, Heidt DG, Dalerba P, et al. Identification of pancreatic cancer stem cells. Cancer Res 2007; 67: 1030-7.

[44] Sikandar SS, Pate KT, Anderson S, et al. NOTCH signaling is required for formation and self-renewal of tumor-initiating cells and for repression of secretory cell differentiation in colon cancer. Cancer Res 2010; 70: 1469-78.

[45] Eramo A, Lotti F, Sette G, et al. Identification and expansion of the tumorigenic lung cancer stem cell population. Cell Death Differ 2008; 15: 504-14.

[46] Singh SK, Hawkins C, Clarke ID, et al. Identification of human brain tumour initiating cells. Nature 2004; 432: 396-401.

[47] Yamashita T, Honda M, Nio K, et al. Oncostatin m renders epithelial cell adhesion molecule positive liver cancer stem cells sensitive to 5-Fluorouracil by inducing hepatocytic differentiation. Cancer Res 2010; 70: 4687-97.

[48] Goodell MA, Rosenzweig M, Kim H, et al. Dye efflux studies suggest that hematopoietic stem cells expressing low or undetectable levels of CD34 antigen exist in multiple species. Nat Med 1997; 3: 1337-45.

[49] Jakubikova J, Adamia S, Kost-Alimova M, et al. Lenalidomide targets clonogenic side population in multiple myeloma: pathophysiologic and clinical implications. Blood 2011;117:4409-19.

[50] Yamazaki J, Mizukami T, Takizawa K, et al. Identification of cancer stem cells in a Taxtransgenic (Tax-Tg) mouse model of adult T-cell leukemia/lymphoma. Blood 2009; 114: 2709-20.

[51] Moshaver B, van Rhenen A, Kelder A, et al. Identification of a small subpopulation of candidate leukemia-initiating cells in the side population of patients with acute myeloid leukemia. Stem Cells 2008; 26: 3059-67.

[52] Salcido CD, Larochelle A, Taylor BJ, Dunbar CE, Varticovski L. Molecular characterisation of side population cells with cancer stem cell-like characteristics in small-cell lung cancer. Br J Cancer 2010; 102: 1636-44

[53] Mimeault M, Johansson SL, Henichart JP, Depreux P, Batra SK. Cytotoxic effects induced by docetaxel, gefitinib, and cyclopamine on side population and nonside population cell fractions from human invasive prostate cancer cells. Mol Cancer Ther 2010; 9: 61730 .

[54] Nakanishi T, Chumsri S, Khakpour N, et al. Side-population cells in luminal-type breast cancer have tumour-initiating cell properties, and are regulated by HER2 expression and signalling. Br J Cancer 2010; 102: 815-26.

[55] Harris MA, Yang H, Low BE, et al. Cancer stem cells are enriched in the sidepopulation cells in a mouse model of glioma. Cancer Res 2008; 68: 10051-9.

[56] Chiba T, Miyagi S, Saraya A, et al. The polycomb gene product BMI1 contributes to the maintenance of tumor-initiating side population cells in hepatocellular carcinoma. Cancer Res 2008; 68: 7742-9.

[57] Chiba T, Kita K, Zheng YW, et al. Side population purified from hepatocellular carcinoma cells harbors cancer stem cell-like properties. Hepatology 2006; 44: 240-51.

[58] Ravandi F, Estrov Z. Eradication of leukemia stem cells as a new goal of therapy in leukemia. Clin Cancer Res 2006; 12: 340-4.
[59] Gal H, Amariglio N, Trakhtenbrot L, et al. Gene expression profiles of AML derived stem cells; similarity to hematopoietic stem cells. Leukemia 2006; 20: 2147-54.

[60] de Jonge-Peeters SD, Kuipers F, de Vries EG, Vellenga E. ABC transporter expression in hematopoietic stem cells and the role in AML drug resistance. Crit Rev Oncol Hematol 2007; 62: 214-26.

[61] Gottesman MM, Fojo T, Bates SE. Multidrug resistance in cancer: Role of ATP-dependent transporters. Nature Reviews Cancer 2002; 2: $48-58$.

[62] de Grouw EP, Raaijmakers MH, Boezeman JB, et al. Preferential expression of a high number of ATP binding cassette transporters in both normal and leukemic CD34+CD38- cells. Leukemia 2006; 20: 750-4.

[63] Krause DS, Van Etten RA. Right on target: eradicating leukemic stem cells. Trends Mol Med 2007; 13: 470-81.

[64] Ross DD. Modulation of drug resistance transporters as a strategy for treating myelodysplastic syndrome. Best Pract Res Clin Haematol 2004; 17: 641-51.

[65] Ross DD. Novel mechanisms of drug resistance in leukemia. Leukemia 2000; 14: 467-73.

[66] Fisher GA, Sikic BI. Clinical studies with modulators of multidrug resistance. Hematol Oncol Clin North Am 1995; 9: 363-82.

[67] Greenberg PL, Lee SJ, Advani R, et al. Mitoxantrone, etoposide, and cytarabine with or without valspodar in patients with relapsed or refractory acute myeloid leukemia and high-risk myelodysplastic syndrome: a phase III trial (E2995). J Clin Oncol 2004; 22: 107886.

[68] Cheung AM, Wan TS, Leung JC, et al. Aldehyde dehydrogenase activity in leukemic blasts defines a subgroup of acute myeloid leukemia with adverse prognosis and superior NOD/SCID engrafting potential. Leukemia 2007; 21: 1423-30.

[69] Steelman LS, Pohnert SC, Shelton JG, Franklin RA, Bertrand FE, McCubrey JA. JAK/STAT, Raf/MEK/ERK, PI3K/Akt and BCR$\mathrm{ABL}$ in cell cycle progression and leukemogenesis. Leukemia 2004; 18: 189-218.

[70] Jaiswal S, Traver D, Miyamoto T, Akashi K, Lagasse E, Weissman IL. Expression of BCR/ABL and BCL-2 in myeloid progenitors leads to myeloid leukemias. Proc Natl Acad Sci USA 2003; 100: 10002-7.

[71] Jiang X, Zhao Y, Smith C, et al. Chronic myeloid leukemia stem cells possess multiple unique features of resistance to BCR-ABL targeted therapies. Leukemia 2007; 21: 926-35.

[72] Jiang X, Saw KM, Eaves A, Eaves C. Instability of BCR-ABL gene in primary and cultured chronic myeloid leukemia stem cells. J Natl Cancer Inst 2007; 99: 680-93.

[73] Roeder I, Horn M, Glauche I, Hochhaus A, Mueller MC, Loeffler M. Dynamic modeling of imatinib-treated chronic myeloid leukemia: functional insights and clinical implications. Nat Med 2006; 12: $1181-4$

[74] Cobaleda C, Gutierrez-Cianca N, Perez-Losada J, et al. A primitive hematopoietic cell is the target for the leukemic transformation in human Philadelphia-positive acute lymphoblastic leukemia. Blood 2000; 95: 1007-13

[75] Michor F, Hughes TP, Iwasa Y, et al. Dynamics of chronic myeloid leukemia. Nature 2005; 435: 1267-70.

[76] Michor F. Mathematical models of cancer stem cells. J Clin Oncol 2008; 26: 2854-61

[77] Michor F. Quantitative approaches to analyzing Imatinib-treated chronic myeloid leukemia. Trends in Pharmacological Sciences 2007; 28: 197-9.

[78] Dingli D, Traulsen A, Michor F. (A)symmetric stem cell replication and cancer. PLOS computational biology 2007; 3: 482-7.

[79] Gorre ME, Mohammed M, Ellwood K, et al. Clinical resistance to STI-571 cancer therapy caused by BCR-ABL gene mutation or amplification. Science 2001; 293: 876-80.

[80] Thomas EK, Cancelas JA, Zheng Y, Williams DA. Rac GTPases as key regulators of p210-BCR-ABL-dependent leukemogenesis. Leukemia 2008; 22: 898-904.

[81] Cancelas JA, Lee AW, Prabhakar R, Stringer KF, Zheng Y, Williams DA. Rac GTPases differentially integrate signals regulating hematopoietic stem cell localization. Nat Med 2005; 11: 886-91.

[82] Gu Y, Filippi MD, Cancelas JA, et al. Hematopoietic cell regulation by Rac1 and Rac2 guanosine triphosphatases. Science 2003; 302: 445-9.

[83] Wang Y, Cai D, Brendel C, et al. Adaptive secretion of granulocyte-macrophage colony-stimulating factor (GM-CSF) mediates 
imatinib and nilotinib resistance in BCR-ABL + progenitors via JAK-2/STAT-5 pathway activation. Blood 2007; 109: 2147-55.

[84] Yang FC, Atkinson SJ, Gu Y, et al. Rac and Cdc 42 GTPases control hematopoietic stem cell shape, adhesion, migration, and mobilization. Proc Natl Acad Sci USA 2001; 98: 5614-8.

[85] Thomas EK, Cancelas JA, Chae HD, et al. Rac guanosine triphosphates represent integrating molecular therapeutic targets for BCRABL-induced myeloproliferative disease Cancer Cell 2007; 12: 467-78.

[86] Hu Y, Swerdlow S, Duffy TM, Weinmann R, Lee FY, Li S. Targeting multiple kinase pathways in leukemic progenitors and stem cells is essential for improved treatment of $\mathrm{Ph}+$ leukemia in mice. Proc Natl Acad USA 2006; 103: 16870-5.

[87] $\mathrm{Li} \mathrm{S}, \mathrm{Li} \mathrm{D}$. Stem cell and kinase activity-independent pathway in resistance of leukaemia to BCR-ABL inhibitors. J Cell Mol Med 2007; 11: 1251-62.

[88] Hu Y, Liu Y, Pelletier S, et al. Requirement of Src kinases Lyn, Hck and Fgr for BCR-ABL1-induced B-lymphoblastic leukemia but not chronic myeloid leukemia. Nat Genet 2004; 36: 453-61.

[89] Danhauser-Riedl S, Warmuth M, Druker BJ, Emmerich B, Hellek M. Activation of Src kinases p53/p56lyn and p59hck by p210bcr/abl in myeloid cells. Cancer Res 1996; 56: 3589-96.

[90] Warmuth M, Bergmann M, Priess A, Hauslmann K, Emmerich B, Hallek M. The Src family kinase Hck interacts with Bcr-Abl by a kinase-independent mechanism and phosphorylates the Grb-2binding site of Bcr. J Biol Chem 1997; 272: 33260-70.

[91] Feinstein E, Cimino G, Gale RP, et al. p53 in chronic myelogenous leukemia in acute phase. Proc Natl Acad USA 1991; 88: 6293-7.

[92] Sill H, Goldman JM, Cross NC. Homozygous deletions of the p16 tumor-suppressor genes are associated with lymphoid transformation of chronic myeloid leukemia. Blood 1995; 85: 2013-6.

[93] Towatari M, Adachi K, Kato H, Sato H. Absence of the human retinoblastoma gene product in the megakaryoblastic crisis of chronic myelogenous leukemia. Blood 1991; 78: 2178-81.

[94] Williams RT, Roussel MF, Sherr CJ. Arf gene loss enhances oncogenicity and limits imatinib response in mouse models of Bcr-Ablinduced acute lymphoblastic leukemia. Proc Natl Acad Sci USA 2006; 103: 6688-93.

[95] Giles FJ, Cortes J, Jones D, Bergstrom D, Kantarjian H, Freedman SJ. MK-0457, a novel kinase inhibitor, is active in patients with chronic myeloid leukemia or acute lymphocytic leukemia with the T315I BCR-ABL mutation. Blood 2007; 109: 500-2.

[96] Cheetham GM, Charlton PA, Golec JM, Pollard JR. Structural basis for potential inhibition of the Aurora kinases and a T315I multi-drug resistant mutant form of Abl by VX-680. Cancer Lett 2007; 251: 323-9.

[97] Schroeder JA, Adriance MC, Thompson MC, Camenisch TD, Gendler SJ. MUC1 alters beta-catenin-dependent tumor formation and promotes cellular invasion. Oncogene 2003; 22: 1324-32.

[98] Haraguchi K, Nishida A, Ishidate T, Akiyama T. Activation of $\beta$ catenin-TCF-mediated transcription by non-receptor tyrosine kinase v-Src. Biochem Biophys Res Commun 2004; 313: 841-4.

[99] Mikesch JH, Steffen B, Berdel, Serve H, Muller-Tidow C. The emerging role of Wnt Signaling in the pathogenesis of acute myeloid leukemia. Leukemia 2007; 21: 1638-47.

[100] Kawano Y, Kypta R. Secreted antagonists of the Wnt signaling pathway. J Cell Sci 2003; 116: 2627-34.

[101] Chim CS, Chan WWL, Pang A, Kwong YL. Preferential methylation of Wnt inhibitor factor-1 in acute promyelocytic leukemia: an independent poor prognostic factor. Leukemia 2006; 20: 907-9.

[102] Reya T, Duncan AW, Ailles L, et al. A role for Wnt signalling in self-renewal of haematopoietic stem cells. Nature 2003; 423: 40914.

[103] Zhao C, Blum J, Chen A, et al. Loss of $\beta$-catenin impairs the renewal of normal and CML stem cells in vivo. Cancer Cell 2007; 12: $528-41$.

[104] Austin TW, Solar GP, Ziegler FC, Liem L, Matthews WA. A role for the Wnt gene family in hematopoiesis: expansion of multilineage progenitor cells. Blood 1997; 89: 3624-35.

[105] van den Berg DJ, Sharma AK, Bruno E, Hoffman R. Role of members of the Wnt gene family in human haematopoiesis. Blood 1998; 89: 3189-202.

[106] Bhardwaj G, Murdoch B, Wu D, et al. Sonic hedgehog induces the proliferation of primitive human hematopoietic cells via BMP regulation. Nat Immunol 2001; 2: 172-80.
[107] Varnum-Finney B, Xu L, Brashem-Stein C, et al. Pluripotent, cytokine-dependent, hematopoietic stem cells are immortalized by constitutive Notch1 signaling. Nat Med 2000; 6: 1278-81.

[108] Hing HK, Sun X, Artavanis-Tsakonas S. Modulation of wingless signaling by Notch in Drosophilia. Mech Dev 1994; 47: 261-68.

[109] Brandts CH, Sargin B, Rode M, et al. Constitutive activation of Akt by Flt3 internal tandem duplications is necessary for increased survival, proliferation, and myeloid transformation. Cancer Res 2005; 65: 9643-50.

[110] Mizuki M, Schwable J, Steur C, et al. Suppression of myeloid transcription factors and induction of STAT response genes by AML-specific mutations. Blood 2003; 101: 3164-73.

[111] Tickenbrock L, Schwable J, Wiedehage M, et al. Flt3 tandem duplication mutations cooperate with Wnt signaling in leukemic signal transduction. Blood 2005; 105: 3699-706.

[112] Lapidot T, Kollet O. The essential roles of the chemokine SDF-1 and its receptor CXCR4 in human stem cell homing and repopulation of transplanted immune-deficient NOD/SCID and NOD/SCID/B2 m(null) mice. Leukemia 2002; 16: 1992-2003.

[113] Willert K, Brown JD, Danenberg E, et al. Wnt proteins are lipidmodified and can act as stem cell growth factors. Nature 2003; 423 : 448-52.

[114] Teixido J, Hemler ME, Greenberger JS, Anklesaria P. Role of beta 1 and beta 2 integrins in the adhesion of human CD34hi stem cells to bone marrow stroma. J Clin Invest 1992; 90: 358-67.

[115] Hirsch E, Iglesias A, Potocnik AJ, Hartmann U, Fassler R. Impaired migration but not differentiation of haematopoietic stem cells in the absence of beta1 integrins. Nature 1996; 380: 171-5.

[116] Lin LI, Lin DT, Chang CJ, Lee CY, Tang JL, Tien HF. Marrow matrix metalloproteinases (MMPs) and tissue inhibitors of MMP in acute leukaemia: potential role of MMP-9 as a surrogate marker to monitor leukaemic status in patients with acute myelogenous leukaemia. Br. J. Haematol 2002; 117: 835-41.

[117] Williams DA, Cancelas JA. Leukaemia: niche retreats for stem cells. Nature 2006; 444: 827-8.

[118] Krause DS Lazarides K, von Adrian UH, Van Etten RA. Requirement for CD44 in homing and engraftment of BCR-ABLexpressing leukemic stem cells. Nat Med 2006; 12: 1175-80.

[119] Jin L, Hope KJ, Zhai Q, Smadja-Joffe F. Dick JE. Targeting of CD44 eradicates human acute myeloid leukemic stem cell. Nat Med 2006; 12: 1167-74.

[120] Yilmaz NH, Valdez R, Theisen BK, et al. PTEN-dependence distinguishes haematopoietic stem cells from leukemia-initating cells. Nature 2006; 441: 475-8

[121] Ma S, Lee TK, Zheng BJ, Chan KW, Guan XY. CD133+ cancer stem cells confer chemoresistance by preferential expression of the Akt/PKB survival pathway. Oncogene 2008; 27: 1749-58.

[122] Zhou J, Wulkuhle $\mathrm{H}$, Zhang $\mathrm{H}$, et al. Activation of the PTEN/mTOR/STAT3 pathway in breast cancer stem-like cells is required for viability and maintenance. Proc Natl Acad Sci USA 2007; 104: 16158-63

[123] Hambardzumyan D, Becher OJ, Rosenblum MK, Pandolfi PP, Manova-Todorova K, Holland EC. PI3K pathway regulates survival of cancer stem cells residing in the perivascular niche following radiation in medulloblastoma in vivo. Genes Dev 2008; 22: 436-48.

[124] Li X, Lewis MT, Huang J, et al. Intrinsic resistance of tumorigenic breast cancer cells to chemotherapy. J Natl Cancer Inst 2008; 100: 672-9.

[125] Shafee N, Smith CR, Wei S, et al. Cancer stem cells contribute to cisplatin resistance in Brca1/p53-mediated mouse mammary tumors. Cancer Res 2008; 68: 3243-50.

[126] Misaghian N, Ligresti G, Steelman LS, et al. Targeting the leukemic stem cell - the holy grail of leukemia therapy. Leukemia 2009; 23: 25-42.

[127] Korkaya H, Paulson A, Charafe-Jauffret E, et al. Regulation of mammary stem/progenitor cells by PTEN/Akt/ $\beta$-catenin signaling. PLOS Biology 2009; 7: 1-14.

[128] Ito K, Bernardi R, Pandolfi PP. A novel signaling network as a critical rheostat for the biology and maintenance of the normal stem cell and the cancer-initiating cell. Curr Opin Genet Dev 2009; 19: 51-9.

[129] McCubrey JA, Abrams SL, Stadelman K, et al. Targeting signal transduction pathways to eliminate chemotherapeutic drug resistance and cancer stem cells. Adv Enzyme Regul 2010; 50: 285-307. 
[130] Lee JY, Nakada D, Yilmaz OH, et al. mTOR Activation induces tumor suppressors that inhibit leukemogenesis and deplete hematopoietic stem cells after Pten deletion. Cell Stem Cell 2010; 7 : 593-605.

[131] Chen C, Liu Y, Liu R, et al. TSC-mTOR maintains quiescence and function of hematopoietic stem cells by repressing mitochondrial biogenesis and reactive oxygen species. J Exp Med 2008; 205: 2397-408.

[132] Gan B, Sahin E, Jiang S, et al. mTORC1-dependent and independent regulation of stem cell renewal, differentiation, and mobilization. Proc Natl Acad Sci USA 2008; 105: 19384-9.

[133] Hashimoto Y, Skacel M, Adams JC. Roles of facin in human carcinoma motility and signaling: Prospects for a novel biomarker? Int $\mathbf{J}$ Biochem Cell Biol 2005; 37: 1787-804.

[134] Tothova Z, Kollipara R, Huntly BJ, et al. FoxOs are critical mediators of hematopoietic stem cell resistance to physiologic oxidative stress. Cell 2007; 128: 325-39.

[135] Miyamoto K, Araki KY, Naka K, et al. Foxo3a is essential for maintenance of the hematopoietic stem cell pool. Cell Stem Cell 2007; 1: 101-12.

[136] Ito K, Bernardi R, Morotti A, et al. PML targeting eradicates quiescent leukaemia-initiating cells. Nature 2008; 453: 1072-9.

[137] Bernardi R, Guernah I, Jin D, et al. PML inhibits HIF-1 $\alpha$ translation and neoangiogeneis through repression of mTOR. Nature 2006; 442: 779-85.
[138] Vicente-Dueñas C, Abollo-Jiménez F, Ruiz-Roca L, et al. The age of the target cell affects B-cell leukaemia malignancy. Aging 2010; 2:908-13.

[139] Kemper K, Grandela C, Medema JP. Molecular identification and targeting of colorectal cancer stem cells. Oncotarget 2010; 1:38795

[140] Pajic M, Kersbergen A, van Diepen F, et al. Tumor-initiating cells are not enriched in cisplatin-surviving BRCA1; p53-deficient mammary tumor cells in vivo. Cell Cycle 2010; 9: 3780-91.

[141] Peng C, Chen Y, Li D, Li S. Role of Pten in leukemia stem cells. Oncotarget 2010;1:156-60.

[142] Bortolomai I, Canevari S, Facetti I, et al. Tumor initiating cells: Development and critical characterization of a model derived from the A431 carcinoma cell line forming spheres in suspension. Cell Cycle 2010; 9:1194-206.

[143] Martelli AM, Evangelisti C, Chiarini F, McCubrey JA. The phosphatidylinositol 3-kinase/Akt/mTOR signaling network as a therapeutic target in acute myelogenous leukemia patients. Oncotarget 2010; 1:89-103.

[144] Adams JR, Schachter NF, Liu JC, Zacksenhaus E, Egan SE. Elevated PI3K signaling drives multiple breast cancer subtypes. Oncotarget 2011 In press. 